\title{
Saturnais: Culto, Religião e Simbolismo
}

\author{
Helena Raquel de França Costa* \\ Altierez Sebastião dos Santos**
}

\section{RESUMO}

Este artigo apresenta uma abordagem sobre os aspectos religiosos, simbólicos e cúlticos presentes no festival romano das Saturnais. Foi destacada a estrutura social e religiosa da Roma antiga, a mitologia em torno do deus Saturno e a festa a ele dedicada. A pesquisa bibliográfica privilegiou a obra do escritor romano Macróbio, do século IV. Destaca-se a continuidade cultural entre antiguidade e contemporaneidade nas dimensões do sagrado e do festivo.

Palavras-chave: saturnais, mitologia, Roma antiga, religião antiga, simbolismo.

\section{SATURNALIAS: WORSHIP, RELIGION, AND SYMBOLISM}

\section{ABSTRACT}

The paper approaches religious, symbolic, and cultic aspects about the Roman festival of the Saturn. The social and religious structure of ancient Rome was emphasized, as well as its mythology around god Saturn and the feast dedicated to him. For the bibliographical, the work of Roman writer Macrobius, fourth century, was used. Eventually, we can point out the cultural continuity between antiquity and contemporaneity in the dimensions of the sacred and the festive.

Key words: festival of the Saturn, mythology, ancient Rome, ancient religion, symbolism.

* Graduada em Letras pela Universidade de Santo Amaro, Registro, São Paulo. Mestranda em Ciências da Religião pela Universidade Metodista de São Paulo. Bolsista CNPQ. Endereço para contato: helena_raquel-rcc@hotmail.com. Curriculum Lattes: lattes.cnpq. br/2132742953487256.

** Graduado em História pela Faculdade de educação São Luís, Jaboticabal, São Paulo. Doutorando em Ciências da Religião pela Universidade Metodista de São Paulo. Bolsista CAPES. Endereço para contato: altierezss@gmail.com. Curriculum Lattes: http://lattes. cnpq.br/3610209535743228. 


\section{Introdução}

A cultura imaterial de um povo tende a revelar os desejos coletivos. As Saturnalia também se encaixam nessa perspectiva. Uma das grandes festividades romanas, revestida por um caráter unitário cívico-religioso-político-social, elas faziam referência a uma utopia passada. Por isso mesmo também apontavam para uma utopia futura, talvez. Aqui vamos nos deter nessa festa cuja genealogia chegou até nós por meio de outras festas que ainda guardam ligações com a festa de Saturno.

Esta análise contempla (i) a estrutura sócio-religiosa da Roma Antiga, (ii) a mitologia de Saturno e (iii) as Saturnalia propriamente ditas. O objetivo é a observação da motivação pública desta festa e de como participavam dela as diferentes e muitas vezes antagônicas classes sociais de Roma. As conclusões são provisórias.

\section{I - A Roma Antiga}

\subsection{Fundação e culto}

Os romanos eram, ao que parece, um povo mesclado, composto por aborígenes, os povos originários de Alba, no Latium, e outros povos que vieram do mar, memória que ficou registrada no mito da Eneida. Esses albanos fundaram o que seria a cidade de Roma sobre outra Urbe, Palantio, de origem grega arcadiana, cidade que apresenta indícios de existência já em cerca de 1000 a. C. Mas os grupos sociais que legaram algum aceno para a história por meio de dados linguísticos ou arqueológicos, vão além dessa marca: “A partir provavelmente de 2200-2100 a.C., grupos de língua indo-europeia ganharam a Itália, onde povoariam sobretudo o centro e o sul da península (povos chamados "itálicos" ou "italiota") e a Sicília (os sículos)" (CARDOSO, 1990, p. 57). Embora haja, segundo Flamarion Cardoso, substratos culturais anteriores a esses (idem) com culturas funerárias acentuadas. De fato, a estrutura inicial e axiológica da sociedade romana deu-se em torno do culto aos antepassados:

os mortos se inseriam numa categoria intermediária entre homens e deuses, já que recebiam culto nos festivais das Parentalia e Lemuria, entretanto, não como indivíduos, mas como um grupo generalizado, sob o 
título de Dii Manes ou diui parentes (literalmente, "os Deuses Manes" ou "os ancestrais divinizados") (BUSTAMANTE, 2011, p. 4).

A origem da cidade de Roma a partir de grupos com cultos semelhantes a estes, ao que tudo indica, advém do período mais recente, de cerca do século X a.C.: "Ora, a população de Palantio subsistiu na nova urbe, e os ritos do culto grego nesta se conservaram. Havia também, no lugar onde mais tarde se ergueu o Capitólio, uma urbe de nome Satúrnia, dada como tendo sido fundada pelos gregos" (COULANGES, 2004, p. 410). Tem-se aí um indício da antiga vinculação de Roma com o culto a Saturno, divindade que está associada a um primeiro a antigo estatuto cívico da cidade.

A base para a fundação das póleis e urbes na antiguidade seguiu aproximadamente os mesmos parâmetros: grupos aparentados que honravam o mesmo antepassado reuniram-se em uma unidade chamada familia (unidade sócio-religiosa), onde o paterfamilias, descendente varão do antepassado, era ao mesmo tempo administrador do culto, das pessoas e dos bens. Esse núcleo cúltico-guerreiro-político centrava-se em torno das divindades lares, que eram propriamente os antepassados.

A religião doméstica dos deuses lares proibia duas famílias de misturarem-se, a não ser que houvesse entre ambas um culto comum. Coulanges (2004, p. 124) intui que essa separação sacral pode ter sido superada entre os grupos de famílias, que se uniram em torno de um antepassado comum e deram origem à cúria (entre os gregos chamada fratria), organização social e civil nascida e sustentada por uma estrutura religiosa em torno de uma divindade maior que os deuses lares e manes. As cúrias, por sua vez, reuniram-se pelas afinidades religiosas e deram origem a uma organização maior, a tribo, também assentada sobre postulados religiosos e o culto a uma divindade comum:

O deus da tribo era ordinariamente da mesma natureza do da fratria, ou do da família. Era um homem divinizado, um herói. Deste herói derivava o nome da tribo: por isso os gregos lhe chamaram herói epônimo. Tinha seu dia de festa anual. A parte principal da cerimônia religiosa consistia em refeição, em que toda a tribo tomava parte (COULANGES, 2004, 126). 
Essa associação religiosa que eram tais grupos percebia grande valor nas festividades em honra das respectivas divindades. Tais cultos agregavam em uma mesma natureza as esferas cívica e religiosa, sendo de tal forma identificadas para o mundo antigo que as leis só teriam validade pelo caráter sagrado que emanava do deus tutelar da Urbe e a vida política consistia em um agir de acordo com as prescrições do culto público (cf. GIORDANI, 1981). As funções do magistrado eram as do sacerdote.

\subsection{A demarcação social do culto}

As pesquisas de Coulanges indicam que o aspecto religioso dava coesão a grupos sociais instáveis como os que formaram as primeiras familiae, cúrias e tribos que depois deram origem à urbe, também reunida em torno de uma divindade comum a todos os grupos, o penates publici:

Devemos pensar bem na excessiva dificuldade existente entre as populações primitivas para fundarem sociedades regulares. O vínculo social não é fácil de se estabelecer entre seres humanos tão diversos, tão livres, tão inconstantes. Para lhes dar regras comuns, para instituir o comando e fazer-lhes acatar pela obediência, para obrigar a paixão a ceder à razão, e a razão individual à razão pública, parece com certeza indispensável existir algo mais forte que a força material, mais respeitável que o interesse, mais seguro que a teoria filosófica, mais imutável que a convenção, alguma coisa existente por igual no fundo de todos os corações e nestes se afirmando com autoridade (COULANGES, 2004, p. 139).

Esse elemento foi o culto aos antepassados, o mesmo culto que havia dado consistência à familia, a religião primeira da qual as regras derivavam. Cada cidade conservara uma estrutura de culto com um sacerdote à frente, que paulatinamente foi sendo destacado da figura do administrador, ainda que um e outro conservassem atribuições compartilhadas. Ocorre que essa religião, desde o período do século VIII a.C, quando os etruscos ocuparam a região entre o Rio Pó e a Campânia, tinha por natureza o princípio de exclusão do estrangeiro, do pertencente a outro culto e mesmo de quem não tinha culto algum, que nesse caso estaria desamparado de segurança jurídica, pois os sacerdotes eram os juízes. "Os antigos tinham livros litúrgicos, mas os de uma urbe não se assemelhavam aos de outra. Cada cidade tinha o seu conjunto de orações 
e práticas, sempre conservadas em grande segredo" (COULANGES, 2004, p. 162), sendo a perda desses segredos litúrgicos considerada um perigo para a segurança da cidade, pois se tratava também da perda em uma dimensão sagrada:

Os antigos esclareciam terem vindo dos deuses as suas leis. Os cretenses atribuíam as suas, não a Minos, mas a Júpiter; os lacedemônios acreditavam como seu legislador, não Licurgo, mas Apolo. Os romanos afirmavam ter Numa escrito como lei o que uma das divindades mais poderosas da Itália antiga, a deusa Egéria, lhe ditara. Os etruscos receberem as suas leis do deus Tagés (COULANGES, 2004, p. 205).

É necessário frisar essa relação íntima entre lei e religião - ou mito, rito e interdito - para se entender o caráter das posteriores festividades romanas. Ritos e festividades em honra dos deuses tutelares da cidade eram proibidos aos estrangeiros e não cidadãos. A exclusão do rito era a exclusão da cidadania. Somente tinham essa cidadania, até por volta do século III a.C, os patrícios descendentes dos fundadores de Roma e de algumas das cidades aliadas. As demais pessoas da Urbe, tais como mulheres, crianças, jovens, escravos, clientes, estrangeiros etc, só poderiam participar do direito romano pela associação com algum patrício, ou pertencendo a ele, ou estando sujeitado a ele pelo clientelismo. Ainda assim a participação na vida pública da cidade era limitada, continuando a esfera da religião vedada aos de fora:

Admitir o estrangeiro entre os cidadãos é dar-lhe participação na religião e nos sacrifícios. Ora, o povo não se sentia inteiramente livre para praticar semelhante ato e assim ficava preso a um escrúpulo religioso; na verdade ele sabia o quanto os deuses nacionais se inclinavam para repelir o estrangeiro e como os sacrifícios talvez se alterassem pela presença do recém-chegado. Facultar o direito de cidade ao estrangeiro era uma verdadeira violação dos princípios fundamentais do culto nacional e por isso mesmo a cidade, no início, se mostrou tão avara em concedê-lo (COULANGES, 2004, p. 213).

Os motivos iniciais para se cultivar a exclusão do estrangeiro podem inicialmente ter passado por questões de segurança e estratégia militar. A continuação da interdição deles, contudo, deve-se à preservação 
do status das famílias fundadoras. A categoria de estrangeiro era então muito ampla: todos os não nascidos das familiae nativas ou sem culto.

Embora a rígida oposição da sociedade romana em estamentos seja característica com a qual os historiadores concordam, nem todos se entendem sobre seu surgimento, como Ciro Flamarion Cardoso, para quem o acirramento entre as classes começou e se acentuou na República (cf. CARDOSO, 1990, p. 62), o que concordaria mais com a memória mítica da Idade de Ouro monárquica de Saturno regendo o Lácio em um período sem escravidão.

De qualquer modo, para os plebeus não existia direito político. Não eram cidadãos, portanto não podiam ser magistrados. Se Coulanges está correto, nos três primeiros séculos de Roma essa estratificação teria permanecido intocada; a assembleia das cúrias compreendia apenas patrícios e seus clientes (no início por representação). À plebe não havia nem a possibilidade de fazer parte do exército (pois ele se organizava em cúrias nesse tempo). A separação entre os plebeus e os patrícios era rigidamente regulada pela lei. “A plebe é uma população desprezível e abjeta, fora da religião, fora da lei, fora da sociedade e da família. O patrício só pode comparar essa existência do plebeu com a do irracional" (COULANGES, p. 265). O contato com o plebeu trazia a impureza. $\mathrm{O}$ casamento entre as classes nem estava legislado pelo simples fato de não se supor tamanha impiedade.

Aos clientes, que estavam ligados às famílias por laços de obediência e serviço, também se aplicavam muitas das distinções, ainda que pudessem acessar parte do direito romano pela intercessão do patrício. Com o tempo, no entanto, os clientes foram se distanciando da nobreza e formando uma só classe com os plebeus. Patrícios e plebeus eram como dois povos muito distintos compartilhando a mesma cidade.

A situação começou a mudar a partir do século $\mathrm{V}$ a. $\mathrm{C}$, quando em 494 a. C., sob ameaça da invasão dos auruncos, os plebeus, que haviam sido admitidos ao exército, que eram a maioria da população, retiraram-se do exército e acamparam no Monte Aventino, exigindo que tivessem um órgão legislador destinado à própria classe, pois estavam simplesmente excluídos - e malquistos - do sistema jurídico. O senado romano, diante da influência e da necessidade dos braços plebeus para a defesa da cidade, reagiu criando a Tribuna da Plebe. Outras revoltas se 
sucederam e até mesmo a tentativa de se fundar uma cidade no Aventino nos anos seguintes, o que ameaçou seriamente a viabilidade de Roma (cf. GIORDANI, 1981). Uma festa universal como as Saturnais não seria possível nesse período.

\section{II - A simbologia de Saturno}

\subsection{Mitologia de Saturno}

Na mitologia, o deus Urano (Céu) inicia sua trajetória unindo-se a Gaia (Terra) e gerando uma raça de Titãs. Temendo os filhos, o impiedoso deus confina-os no ventre de Gaia. No entanto, cansada do marido, Gaia decide poupar o filho mais novo, Saturno, para que esse a salvasse depois. Gaia entrega uma foice para Saturno quando ele cresce e, com ela, decepa o falo paterno, toma o poder e liberta os irmãos Titãs. Temendo a maldição do pai, Saturno resolve devorar os filhos para não sofrer destino semelhante. Até que sua esposa Cibele, sua irmã, o engana fazendo-o devorar uma pedra no lugar do sexto filho, Júpiter. Júpiter (identificado com Zeus), foi criado pelas ninfas, escondido nas grutas, até o dia em que soube de sua origem pelos dizeres de uma águia. Então retorna à casa paterna e, disfarçado de escanção, serve a Saturno uma poção que o faz vomitar os filhos devorados: Juno, Plutão, Netuno, Vesta e Ceres.

Diante da ameaça dos filhos, Saturno convoca seus irmãos Titãs e trava uma guerra contra os filhos. Júpiter e seus aliados se organizaram no monte Olimpo e com a ajuda dos Ciclopes, se ocultaram numa nuvem prodigiosa e numa batalha feroz, Júpiter venceu a guerra, precipitando montanhas sobre os Titãs, que foram acorrentados pelos Ciclopes nas profundezas do Tártaro (Cf. FRANCHINI \& SEGANFREDO, 2007. p. 10-17). Essa queda de Júpiter teria encerrado um período de prosperidade para a raça humana, muito diverso de quando o deus foi morar com os seres humanos no Lácio, onde foi recebido por Jano, que simpatizou-se muito do estrangeiro recém-chegado, admitindo-o não apenas à sua amizade, mas ao governo daquela terra: 
Então o poder real estava concentrado apenas em Janus, que, acredita-se, mostrava uma dupla face, de modo que ele viu as coisas que estavam à sua frente e as que estavam atrás dele; que indubitavelmente se refere à prudência e sagacidade do rei, que conhece o passado e prevê o futuro [...]. Jano, então, tendo recebido Saturno, que chegou por mar, com toda a hospitalidade, aprendeu com ele a técnica agrícola, tendo melhorado o modo de vida, que antes de conhecer as colheitas, era selvagem e áspero. Por isso, associou Saturno ao seu trono. Além disso, tendo sido Jano o primeiro a cunhar uma moeda, também observou deferência em relação a Saturno, de modo que, pelo fato deste ter chegado de barco, Jano gravou por um lado [da moeda] um retrato de sua própria cabeça, é claro, mas do outro, um navio, para transmitir à posteridade a memória de Saturno. Á moeda se mantém assim até hoje e [a vemos] em um jogo de azar, quando crianças, jogando denários no ar, exclamam "Cabeça" ou "Barca", sendo o jogo um atestado de antiguidade. Remaram juntos e em boa harmonia e fundaram conjuntamente cidades vizinhas, além de Maron (MACROBIO, 2010, p.147).

A história do culto a Saturno na urbe romana deixou narrativas devocionais e afetivas como essa, mas não legou registros claros, mas o templo dedicado ao deus ao pé do Monte Capitolino teria sido fundado pelos cônsules Aulo Semprônio e Marco Minúcio em 497 a.C. Foram estes magistrados que teriam instituído as Saturnais (AGNOLON, 2013, p. 25). O próprio Macróbio narra alguns fatos sobre o templo:

Agora vou dizer algumas palavras sobre o templo de Saturno. De acordo com as minhas fontes, Túlio Hostílio, após a obtenção de um duplo triunfo sobre os albaneses e uma terceira vitória sobre os Sabinos, consagrou um santuário para Saturno em cumprimento de um voto, instituiu pela primeira vez as Saturnalia em Roma, embora Varro no sexto livro "sobre os edifícios sagrados", escreve que o rei Lucio Tarquinio encomendou a construção de um templo em honra de Saturno ao Fórum, e que o ditador Tito Lárcio consagrou este templo durante a Saturnalia. Também não me escapa que Gelio escreva que o Senado decretou a construção de um templo em homenagem a Saturno e confiou a tarefa ao tribuno militar Lucio Furio. O templo também tem um altar em frente ao Cenáculo. [...] (MACROBIO, 2010, p. 152).

Além de Macróbio, outros autores indicam a possibilidade de o Monte Capitolino ter sido, outrora, chamado de Satúrnia, fixando ainda mais a ligação de Saturno, enquanto divindade, como culto precedente à fundação da Urbe. A estátua de Saturno que, acreditava-se ter sido 
feita a mando de Jano, trazia em suas mãos uma foice simbolizando sua ligação com a criação da agricultura e a revolta contra o pai.

\subsection{A alegoria de Saturno}

Para uma sociedade profundamente religiosa como a romana, a religião ofereceu distintas possibilidades de alegorias que retratassem suas utopias e desejos mais imediatos. O culto a Saturno, especialmente na festa do deus, tinha um caráter utópico cultivado pela sociedade. Antigas tradições romanas, transmitidas sobretudo por poemas de heróis fundadores, como os compostos por Virgílio para a Eneida fazem menção à mítica era em que Saturno teria reinado sobre o Lácio, a Idade do Ouro sempre lembrada pela cultura e sociedade romanas, como foi registrado na História por meio da cunhagem de moedas com motivos saturninos, por exemplo (AGNOLON, 2013, p. 33).

Os romanos queriam que o templo de Saturno guardasse o erário público, porque, durante a estadia do deus na Itália, não foi cometida, segundo a tradição, não roubo no seu território, ou porque, sob seu reinado, a propriedade privada não existia (MACROBIO, 2010, p. 152).

A memória de uma época boa, lembrada pela posteridade, era uma grande motivação das Saturnalia (cf. BULFINCH, 2002, p. 17). Macróbio escreve, no século IV, fim do império romano, período marcado pela decadência.

Saturnus faz referência na Antiguidade, e nas tradições posteriores, como na Idade Média e no Renascimento, ao deus cujo reinado, até ser destronado por Júpiter, foi símbolo de abundância e felicidade plenas para a humanidade; b) ao rei mítico do Lácio, entidade civilizatória que trouxe consigo as artes agrárias e o bom governo [...] (AGNOLON, 2013, p. 17).

Ele voltaria para reestabelecer um novo período de prosperidade? Seria essa utopia um desejo dos romanos dos últimos séculos do império? A memória do reinado de Júpiter na Idade do Ouro pode ter relações também com as tensões que a sociedade romana acumulava em sua complexidade ao longo dos séculos. Uma era utópica onde o mal não subjugava a Terra, não havia nem dor e nem velhice, as pessoas morriam serenamente e havia abundância de bens. 
Para os romanos "O mesmo Saturno que destrona o pai, devora os filhos, é para os homens (sic) a lembrança longínqua de uma época de plena felicidade tendo a paz como corolário" (AGNOLON, 2013, p. 29). Reverenciado como o exemplo do rei que é justo e responsável pelo avanço da civilização com a agricultura, é aquele que também deu bases jurídicas à Cidade. Diante de tal hierofania até as guerras eram suspensas.

Outra virtude evocada aos romanos por Saturno é a da concórdia, religiosamente buscada por eles inclusive como condição da existência da Urbe. A proximidade e companheirismo destacados nas narrativas da amizade entre Jano e Saturno eram inspiradoras. Tendo Jano chegado ao Lácio muito antes, quando Saturno, estrangeiro, chegou, travaram forte amizade, admiração e respeito, de forma que Jano teria dividido com o novato o governo das terras ancestrais. Quando Saturno se foi, Jano honrou essa amizade:

Com o desaparecimento de Saturno, Jano decide imortalizar, transmitir à posteridade a memória dele. Além das moedas que já cunhara, determina que se elevem mais ainda as honras do deus: passa a chamar "Satúrnia" todo o Lácio, ergue-lhe um altar, institui as Saturnais (AGNOLON, 2013, p. 44).

\section{III - As Saturnais}

\subsection{Uma tradição, várias tradições}

Um dos relatos que mais parecem espelhar a atmosfera romana do século IV e apresentar o que teriam sido as Saturnais é Macróbio ${ }^{1}$, que testemunhou o declínio do Império Romano e a ascensão da Igreja, que ocupava o vazio institucional do Estado, Macróbio faz parte de um movimento de resistência a essa situação, por isso ressalta em suas obras os valores pagãos e as tradições romanas (ANDRADE, 2016).

\footnotetext{
1 Entre suas funções públicas, foi senador, Vigário na Hispania, procônsul na África e prefeito do pretório, como informa Antolin (2010), que também nos faz saber que Macróbio foi um autor popular na Idade Média e suas obras (sobretudo Comentário a "Os sonhos de Cipião") alcançaram numerosas publicações até o século XVII. "Macrobio era muy leído y estimado como autoridad en ciertas materias, en especial, astronomía y geografía, y en la interpretación de los sueños" (ANTOLIN, 2010, p. 46).
} 
A redação das Saturnália ${ }^{2}$ teria se dado em 395 retratando o festival acontecido no verão de 384 (idem, 2010, p. 8; 27) com o intuito de transmitir às gerações vindouras a tradição romana. Por isso o caráter pedagógico e enciclopédico da obra, dedicada por Macróbio a seu filho Eustáquio. Ele entendia que salvar a cultura romana significava salvar a cultura clássica do esquecimento. Por volta do século IV a conformação social cada vez mais instável e complexa do império indicava o caos. Por isso Macróbio condensou vasto número de informações, alegorias, poemas, recordações da Urbe.

Além das referências que nos chegaram por meio da obra de Macróbio sobre as Saturnais, há várias menções de escritores antigos a esses dias de festejo. Como os livros do poeta Marcial, por exemplo. Xênia e Apoforeta foram escritos especialmente para que seus versos fossem usados nas Saturnais, de onde seriam extraídos versos irônicos, enigmáticos, de duplo sentido ou cômicos que estavam destinados a serem enviados junto com presentes aos amigos (cf. AGNOLON, 2013). Xênia e Apoforeta são datados por volta de 83 a 85 d. C. Neles são reunidos diversos poemas onde são registrados diversos dados importantes quanto à realização das Saturnais, como a distribuição de presentes e lembranças durante os festejos. Assim como era costume em celebrações romanas as ofertas de alimentos e objetos utilizados nos banquetes.

A data de celebração das Saturnalia variou entre os romanos. Originalmente elas teriam ocorrido anualmente no dia 19 de dezembro; com a reforma juliana do calendário, que acrescentou dois dias ao mês de dezembro, elas passaram para o dia 17. No século I a.C. iniciavam-se no dia 17 de dezembro do calendário juliano e terminavam no dia 23. Augusto, preocupado com a extensão do recesso, tentou diminuir a festa para três dias e Calígula tentou implantar cinco dias a mais, perfazendo oito dias, mas a tradição de consagrar uma semana às $S a$ turnalia permaneceu inalterada, inclusive porque o tempo era propício: fim das colheitas, descanso da terra e encerramento do ciclo produtivo (cf. ANTOLIN, 2010).

\footnotetext{
2 À semelhança do Banquete de Platão, As Saturnais retrata um simposium. Os personagens reunidos pelo autor, eram sumidades da época em temas relacionados à tradição educacional e cultural romana: gramáticos, reitores, professores, filósofos, escritores. A única exceção é o penetra Evangelho, que sendo um invasor, de maus modos e intolerante, é retratado como uma alegoria do cristianismo.
} 
O dia original havia sido escolhido em função da Opalia, em honra à deusa Ops, que personificava a abundância e os frutos da terra, e era a consorte de Saturno. Como as duas divindades representavam o produto dos campos e pomares, eles também representavam o céu e a terra. Era por esta razão, segundo Macróbio, que os festivais eram celebrados ao mesmo tempo, com os cultores de Ops sempre sentados em oração, de forma a tocar a terra, mãe de todos (LEITE, 2006, p.103).

As Saturnalia eram sem dúvida a festividade mais popular do calendário romano. Catulo as descreve como "o melhor dos dias", no poema 14, gracejando sobre os presentes que seus amigos davam durante as festividades saturninas:

Nei te plus oculis meis amorem,

Iocundissime Calue, munere isto

Odissem te odio uatiniano;

Nam quid feci ego quidue sum locutus,

Cure me tot male perdere poetis?

Isti dei mala multa dente clienti,

Qui tantum tibi misit impiorum.

Quod si, ut suspicor, hoc nouum ac repertum

Munus dat tibi Sulla literator,

Non est mi male, sed bene ac beate,

Quod non dispereunt tui labores.

Dei magni, horribile est sacrum libellum!

Quem tu scilicet ad tuum Catullum

Misti, continuo ut die periret

Saturnalibus, optimum dierum!

Se não te amasse mais do que a meus olhos,

Felicíssimo Calvo, por tal presente

Eu te odiaria com o ódio de Vatínio;

Pois o que eu fiz, o que eu falei,

Para que me perdesses com tão maus poetas?

Que os deuses mandem muitos males ao teu cliente

Que enviou a ti tantas coisas ímpias. 
Se, conforme suspeito, este presente novo e inacreditável

Te dá Sila, o gramático, não me parece mal,

Mas sim bom e belo

por não desperdiçares teus esforços.

Grandes deuses, que livro horrível e infame!

Este que sem dúvida tu deste a teu Catulo para que ele morra subitamente

Neste dia de dons, Saturnais, melhor dos dias!

(CATULO apud LEITE, 2006, p. 104-5).

O comércio de imagens, as sigillaria, outra tradição do período, caracterizou as Saturnais pela troca de pequenos presentes. As sigillaria, pequenas estatuetas e peças, eram entregues como bom augúrio pelo ciclo do ano produtivo que chegava ao término em dezembro (cf. ANTOLIN, 2010, p. 174). A princípio a troca de sigilaria acontecia após as Saturnalia mas com o decorrer do tempo passou a integrá-la.

A tradição dos jogos, proibidos durante todo o ano, eram liberados durante as Saturnais: podia-se jogar em troca de nozes e não dinheiro. Jogavam-se dados, adivinhações, disputava-se e apostava-se sobre tudo. Rinhas eram montadas com aves e até lutas eram marcadas.

A inversão dos papéis talvez não preencha a expectativa de "inversão social" como nossa ótica poderia filtrar a partir da atualidade (cf. FURLANI, 2012, p. 194). O plebeu poderia ser nobre e ser servido pelo seu senhor; o escravo poderia lançar injúrias e brincadeiras sarcásticas sobre seus senhores sem ser punido depois, não significando, no entanto, que havia um parâmetro para regular a inversão dos papéis. Fechadas as portas ao anoitecer, tudo poderia continuar como sempre fora.

Brincadeiras eróticas, liberdade exacerbada, livre expressão: as Saturnais eram dias em que as regras podiam ser quebradas. A festa era como um grande teatro, onde se dramatizava o mundo sob o domínio temporário de Saturno:

As Saturnais iniciavam com um sacrifício do templo dedicado ao deus situado no Foro, na ara Saturni. Em seguida, ocorriam um banquete solene (lectisternium) e um festim público (conuiuium publicum) patrocinados pelo tesouro, em que senatores e équites abandonavam suas insígnias, títulos honoríficos e qualquer coisa que os distinguisse hierarquicamente 
- segundo Tito Lívio, no início, eram os próprios senadores encarregados de preparar o lectisternium - "e os próprios senadores preparavam os leitos", et eum lectum senatores strauerunt (AGNOLON, 2013, p.75).

Seguia-se o ritual com os gritos de proclamação do festim, os banhos matutinos de purificação, os divertimentos, a teatralização do retorno da Idade do Ouro. O trabalho do campo era interrompido, era tempo de consumir os frutos da terra, até porque o próprio tempo, o inverno, impedia o plantio. Fazia-se necessário esperar pelo mês de fevereiro.

O culto de Saturno foi reorganizado na Segunda Guerra Púnica (218-221 a. C.), juntamente com outros cultos e sacrifícios aos deuses, como maneira de aplacar sua ira e para apaziguar as tensões do povo (cf. ANTOLIN, 2010). Sendo assim, gracejos saturnalícios teriam caráter apotropaico. A utilização de placas de tábuas de bronze contendo as regras que deveriam ser lidas, demonstra a ambiguidade do deus. As plaquinhas de chumbo encontradas espalhadas por cemitérios e pântanos, contendo imprecações do mal, possuíam um complemento nas tabuinhas em forma de bronze, tidas como amuletos para afastar o mal e trazer bons augúrios (cf. AGNOLON, 2013, p. 59).

\subsection{Suspensão das regras: reforço da divisão social?}

O espírito de liberdade, a lascívia, o erotismo das Saturnais, não refletiam os costumes rotineiros do povo romano. Eram dias licenciados, onde se podia fazer o que não era moralmente aceito nos demais dias do ano. Carregando em si muito mais o respeito às práticas ancestrais do que a entrega aos prazeres da festa.

Apesar de as Saturnais, via de regra, serem reconhecidas como a prerrogativa de ser um tempo de "iguais", na prática, o distanciamento social entre classes não era completamente interrompido nos dias da festa. Havia ressalvas por parte dos paterfamilias e cada senhor mantinha em seus domínios suas próprias regras. Como Plínio que permitia a celebração aos seus escravos, porém sem participar com eles. Ou ainda, Sêneca, que celebrava e banqueteava com seus servos, porém com a concepção do senhor que tem a obrigação de cuidar daqueles que estão sob sua tutela. Ou seja, a divisão de classes não somente permanecia presente durante as Saturnais, como era reforçada durante a mesma, sendo as residências como pequenas repúblicas (cf. MACROBIO, 2010). 
Os escravos celebravam perante a ação generosa de seu senhor, podiam desfrutar por um breve período de tempo de suas regalias, mas não todos os escravos, pois alguns deles deveriam estar de prontidão para continuar o serviço da domus. Na prática a hierarquia continuava vigente já que havia urgências que não podiam ser interrompidas como a (o) dos (as) cozinheiros, os que serviam o alimento, o entretenimento, incluindo aí a satisfação sexual dos senhores, conforme indicam os clássicos epigramas de Marcial (AGNOLON, p.118-20).

A folga no contrato social romano, com vários níveis de servidão, era necessária para aliviar as tensões, sendo, por exemplo, uma forma de evitar que o paterfamilias viesse a ser vítima de seus clientes, dependentes ou escravos, algo que era possível. A inversão de papéis, uma vez representados e com essa consciência de representação, era uma ferramenta de afirmação das posições já estabelecidas. O bom imperador seria aquele capaz de conceder atos de generosidade para com a plebe, "Contrariamente, o mau imperador era aquele incapaz de manter e reforçar a hierarquia e conceder honrarias devidas a todos, de acordo com o lugar que ocupam na cena social" (AGNOLON, 2013, p.112).

A generosidade do imperador, ou do senhor, era na justa medida de sua continência perante os papéis sociais. Como Augusto, que permitia toda espécie de divertimentos e trocas de presente entre seus escravos, no entanto sem se entregar aos excessos que não lhe convinham (cf. ANTOLIN, 2010).

Contudo, devido a diversos fatores, por volta dos séculos III e IV, a festa de Saturno não era mais uma unanimidade dos romanos, mesmo entre os pagãos. Houve mudanças profundas, talvez uma degeneração das motivações, que indicavam a busca pelo desregramento e excessos para além da troca de papéis sociais e das fantasias. Saturnalia teria se transformado em sinônimo de orgia. Leite nos informa parte da correspondência de Sêneca com Lucílio sobre essa mudança:

É agora o mês de dezembro, em que a maior parte da cidade está em festa. Rédeas soltas são dadas para a dispersão pública, em qualquer lugar que se vá são ouvidos os sons de grandes preparações, como se houvesse realmente uma grande diferença entre os dias devotados a Saturno e os dias comerciais (LEITE, 2006, p. 108). 
A moral cristã e antes a estóica, condenaram as Saturnalia pelo exposto e por inadequação às suas visões de mundo. Contudo, mesmo desaparecendo, a Festa de Saturno legou à posteridade as festas do entrudo e do carnaval e talvez alguns elementos do Natal.

\section{Conclusões}

Apesar disso, as Saturnais eram "A Festa dos Escravos", dias de licença e liberdade, ao mesmo tempo de controle social sacralizado. A encenação do retorno ao tempo mítico da Idade do Ouro. Trazendo em si a dualidade do deus Saturno, exemplo de bondade, justiça e avanço civilizatório, ao mesmo tempo que deus implacável, capaz de influenciar para o mal e que mais tarde, embora destronado pelo cristianismo, assim como outros deuses romanos, subsistirá implicitamente nos costumes e simbologias incorporados às festas da Igreja.

Tratando-se de Roma, tão distante e tão próxima de nós, é difícil compreendermos de forma comparativa os processos que ocorreram em mundo e em um tempo distintos do nosso e assentados em um mundo e um tempo ainda mais distanciados. Até mesmo por isso é necessário que se dedique ao passado da civilização um olhar sem pressuposições e sem conceituações já determinadas cartesianamente.

$\mathrm{O}$ enlace profundo entre religiosidade e vida civil da Roma antiga, que está em nossas raízes culturais, talvez teria algo a nos dizer sobre a relação entre religião e política nesta nossa sociedade e na forma como conduzimos essa relação.

\section{Referências}

AGNOLON, Alexandre. A Festa de Saturno: O Xênia e Apoforeta de Marcial. Tese (Doutorado em Letras Clássicas) - Faculdade de Filosofia, Letras e Ciências Humanas, Universidade de São Paulo. São Paulo, 2013.

ANDRADE, Jenny Barros. "Corpo E Festa Na Antiguidade Tardia: O Convivium Nas Saturnais, De Macróbio". In: Cadernos de Clio, Curitiba, v. 7, $\mathrm{n}^{\mathrm{o}} .1,2016$.

ANTOLIN, Fernando Navarro. "Introdução, tradução e notas". In: MACROBIO. Las Saturnales. Madrid: Editorial Gredos, 2010.

BUSTAMANTE, Regina Maria da Cunha. "Festa das Lemuria: os mortos e a religiosidade na Roma Antiga". In: Anais do XXVI Simpósio Nacional de História - ANPUH, São Paulo, julho 2011. 
BULFINCH, Thomas. O Livro de Ouro da Mitologia: História de deuses e heróis. Trad. David Jardim Júnior. 26a Edição. Rio de Janeiro: Ediouro Publicações, 2002.

CARDOSO, Ciro Flamarion S. A Cidade-Estado antiga. São Paulo: Ática, 1990.

COUlangeS, Fustel de. A Cidade Antiga. Trad. Fernando de Aguiar. São Paulo: Martins Fontes, 2004.

FLORES, Moacyr. "Do Entrudo ao Carnaval". In: Estudos Ibero-Americanos. PUCRS, v. XXII, n. 1, p. 149-161, 1996.

FRANCHInI, A.S.; SEGANFredo, Carmen. As Melhores Histórias Da Mitologia: Deuses, heróis, monstros e guerras da tradição greco-romana. $9^{\mathrm{a}}$ Edição. Porto Alegre: Digital Source, 2007.

FURLANI, João Carlos. "Celebrações de família na Antiguidade: o casamento na concepção romana". In: LEITE, Leni Ribeiro et alii. Rito e celebração na Antiguidade. Vitória: PPGL, 2012.

GIORDANI, Mário Curtis. História de Roma. Petrópolis: Vozes, 1981.

LEITE, Leni Ribeiro. "Saturnais: tempo de presentes". In: Intertextualidade e Pensamento Clássico: Anais da XXV Semana de Estudos Clássicos. Ana Thereza Basílio Vieira e Auto Lyra Teixeira (orgs.), Dept ${ }^{\circ}$ de Letras Clássicas da Faculdade de Letras da UFRJ. Rio de Janeiro: Serviço de Publicações/ FL-UFRJ, 2006.

MACROBIO. Las Saturnales. Introdução, tradução e notas de Fernando Navarro Antolin. Madrid: Editorial Gredos, 2010. 